\title{
CLASSIFICATION OF ENGINEERING STUDENTS' SELF-EFFICACY TOWARDS VISUAL-VERBAL PREFERENCES USING DATA MINING METHODS
}

\author{
Citra Kurniawan, Punaji Setyosari, Waras Kamdi, Saida Ulfa \\ State University of Malang, Indonesia \\ E-mail: airakurniawan@gmail.com, punaji.setyosari.fip@um.ac.id, \\ waras.ft@um.ac.id, saida.ulfa.fip@um.ac.id
}

\begin{abstract}
The purpose of this research was to build a classification model and to measure the correlation of selfefficacy with visual-verbal preferences using data mining methods. This research used the J48 classifier and linear projection method as an approach to see patterns of data distribution between self-efficacy and visual-verbal preferences. The measurement of the correlation of engineering students'self-efficacy with visual-verbal preferences using the data mining method approach gets the result that self-efficacy does not correlate with visual-verbal preferences. However, engineering students'self-efficacy influences the achievement of initial learning outcomes. Visual-verbal preference is more influenced by students' interest in images so it can be concluded that self-efficacy affects the initial results of learning but does not have a correlation with visual-verbal preferences. The results of the decision tree provide the results that are easily understood and present a correlation between self-efficacy and visual-verbal preferences in a visual form.
\end{abstract}

Keywords: self-efficacy, visual-verbal preferences, data mining.

\section{Introduction}

Every student has different levels of self-efficacy because they have different initial abilities and learning experiences. Self-efficacy influences people 's belief to face failure and try harder in achieving success. Success can build a robust belief in the level of confidence. If someone achieves success easily, then he/she are easily discouraged by failure because the level of confidence requires experience to overcome the problems that occur. The experience gained when dealing with problems becomes capital to help improve self-efficacy (Bandura, 1994). Self-efficacy refers to the ability of someone who uses prior experience references to solve problems (Boswell, 2013). Individuals who have high self-efficacy have high confidence to deal with problems, while individuals with low self-efficacy have fears of facing failure (Wu, Tsai, \& Wang, 2011). Students try to process information and appraise their self-efficacy from ability and learning experience. The success of students to overcome problems can increase selfefficacy and reduce failure (Schunk, 2003). Self-efficacy is formed from experience, common experiences, social persuasions, and physiological reactions (Jordan, Amato-henderson, Sorby, \& Donahue, 2011). Self-efficacy in the engineering field is very important. Bandura (1997) explained that self-efficacy determines the action to be chosen, how much effort is made to solve the problem, how can they survive in failure and realize the level of self-achievement (Bandura, 1997; Marra \& Bogue, 2006). Engineering students need quantitative skills to prepare 
Citra KURNIAWAN, Punaji SETYOSARI, Waras KAMDI, Saida ULFA. Classification of engineering students' self-efficacy towards visual-verbal preferences using data mining methods

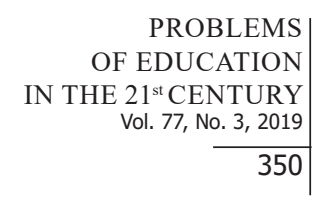

themselves to face problems in engineering courses. Self-efficacy contributes to academic performance even though the factors of problem-solving ability and intellectual ability also influence learning outcomes (Aleta, 2016). The factors that influence confidence in success in engineering students are mastery experiences, vicarious experiences, social persuasions, and physiological states. Classroom and curricular practice influence students' engineering to have self-confidence, retention, and success (Hutchison, Follman, \& Bodner, 2005). Bandura revealed that engineering self-efficacy was measured using the developed self-efficacy scale (Bandura, 2006). Carberry et al. (2010) showed three findings to measure self-concept in student engineering, namely (1) measurement design considers the factors of self-efficacy, motivation, anxiety, and outcome expectation; (2) self-efficacy depends on the experience of the engineer students; (3) High correlation between self-efficacy with motivation, expertise and outcome expectation (Carberry, Hee-Sun, \& Ohland, 2010).

Engineering courses are often associated with things related to configuration, symbols, codes, and topology. Engineering students have process information based on their preferences. When Engineering students have presented a content consisting of images and text, it will try to process which content matches their preferences (Kurniawan, Setyosari, Kamdi, \& Ulfa, 2018). If a student who has visual preferences processes information from the content, then the first time he is looking for is image content. If the content displayed is only in the form of text, he will still try to process information even though the content does not match his learning preferences (Peterson, 2016; Plass, Chun, Mayer, \& Leutner, 1998). Visualization is essential in learning. Visualization can simplify the information that is difficult to understand (Sudatha, Degeng, \& Kamdi, 2018). A student always has different preferences in processing information. Also, students also have self-efficacy in dealing with problems in the information processing process. Someone who has high self-efficacy tends to be able to make more efforts in processing information if the information presented does not match his preferences. Therefore, research is needed, which aims to identify the self-efficacy that a person has seen from the visual-verbal preferences approach.

\section{Problem of Research}

Data mining methods aim to determine the classification model by determining data classes and grouping examples based on similarity attributes. Previous research measured correlation using descriptive statistical methods, such as in the research of measuring cognitive style visualizer correlations to the achievement of learning outcomes in design modeling and performance (Pektaş, 2013). In the research Pektaş (2013) used the analysis of variance analysis (ANOVA) to determine whether cognitive style has any effect on design modelling and performance. However, descriptive statistics method is not optimal for drawing correlations in the form of data visualization so that the tendency of one variable/class cannot be seen. Therefore, the measurement of correlation of self-efficacy to visual-verbal preferences with data mining methods is needed as an alternative method besides descriptive statistical methods. This research was tried to build a classification model for experimental data that has been collected. This research discusses the analytical method for measuring the correlation of engineering students' self-efficacy if it is associated with visual-verbal preferences.

\section{Research Focus}

The focus of this research was: (1) building a data mining classification model, and (2) measuring the correlation of engineering students' self-efficacy and visual-verbal preferences using data mining methods. 
Citra KURNIAWAN, Punaji SETYOSARI, Waras KAMDI, Saida ULFA. Classification of engineering students' self-efficacy towards visual-verbal preferences using data mining methods

\section{Research Methodology}

\section{General Background}

This study used experimental research with data mining methods for educational data. Data mining in this research is a classification technique assisted by WEKA data mining software (Abernethy, 2010; Witten, Frank, Hall, \& Pal, 2017) and Orange data mining (Demšar et al., 2013). Data mining classification in this research uses decision tree-J48 (WEKA) and Linear Projection (Orange) classification techniques. WEKA data mining provides various methods for classifying (Kabakchiev et al., 2017). This research used Decision Tree-J48 to do classification. Decision tree-J48 is the implementation of the C4.5 algorithm in WEKA data mining. The C4.5 algorithm has a method for breaking nodes into several nodes based on the similarity of attribute data. Linear projections provide an overview of the linearity correlation between engineering students' self-efficacy and visual-verbal preferences displayed in graphical form.

\section{Sample}

Participants in this research were 250 engineering students, with details of 72 female participants and 178 male participants, as shown in Table 1.

\section{Table 1. Distribution of participant.}

\begin{tabular}{lccc}
\hline & \multicolumn{3}{c}{ Preferences } \\
\cline { 2 - 4 } Self-Efficacy & Verbal & Visual & Total \\
\hline High Self-efficacy & & & \\
Female & 4 & 28 & 32 \\
Male & 26 & 47 & 73 \\
Low Self-efficacy & & & \\
Female & 12 & 28 & 40 \\
Male & 28 & 77 & 105 \\
\hline
\end{tabular}

Figure 1 shows the preferences and attributes of self-efficacy for each gender, where participants who had high self-efficacy consisted of 32 female and 73 male. Participants who had low self-efficacy included 40 female and 105 male. Preference has two attributes, namely visual and verbal, while self-efficacy has two attributes, namely high and low. The measurement of the self-efficacy scale uses the self-efficacy instrument developed by Bandura (2006), where students who obtain value on means from the measurement results are grouped into groups of students with high self-efficacy, while students who obtain the value under means from the measurement results grouped into groups of students with low self-efficacy.

\section{Instrument and Procedures}

Participants in this research were given several tests aimed at measuring the preferences of visual-verbal, self-efficacy, and pre-tests. Test results were processed using data mining methods, namely decision trees, and linear projection classifications. Visual-verbal preference was measured using a visual-verbal questionnaire (VVQ) developed by Richarson (1977) which contained the VVQ category (Richardson, 1977) and Kirby (1988) that developed question item of VVQ (Kirby, Moore, \& Schofield, 1988). While the self-efficacy measurement used a 
Citra KURNIAWAN, Punaji SETYOSARI, Waras KAMDI, Saida ULFA. Classification of engineering students' self-efficacy towards visual-verbal preferences using data mining methods

OF EDUCATION

IN THE $21^{\text {st }}$ CENTURY

Vol. 77, No. 3, 2019

self-efficacy questionnaire (Bandura, 2006). Meanwhile, the analysis of the pre-test results in this research has used the questions given in the Cisco Networking Academy Program, Chapter 1 to measure the initial value of the pre-test (Cisco Systems, 2003). Data mining process data classified into five classes, each of which is self-efficacy, gender, interest in images, preferences, and pre-test results, can be seen in Figure 1.

\begin{tabular}{|c|c|c|c|c|}
\hline & Name & Type & Role & Values \\
\hline 1 & Self_Efficacy & C categorical & target & High, Low \\
\hline 2 & Gender & C categorical & feature & Female, Male \\
\hline 3 & Interest_in_Imag... & C categorical & feature & Interest with Image, No interest with image \\
\hline 4 & Preferences & C categorical & feature & Verbal, Visual \\
\hline 5 & Pre-Test & $\mathbb{N}$ numeric & feature & \\
\hline
\end{tabular}

\section{Figure 1. Class of data.}

Self-efficacy has two attributes, namely "high" and "low," gender has two attributes, namely "male" and "female," image interest has two attributes, namely "interested" and "not interested," preference has two attributes, namely "verbal" and "visual.

\section{Data Analysis}

The classification phase in data mining consists of three stages, namely (1) experimental data; (2) modelling; (3) evaluation (Demšar et al., 2013). Experimental data were presented data in five classes and their attributes. Experimental testing data use 10-fold cross validation because this test is effective for limited data (Kabakchiev et al., 2017). The classification developed in this research can be seen in Figure 2.

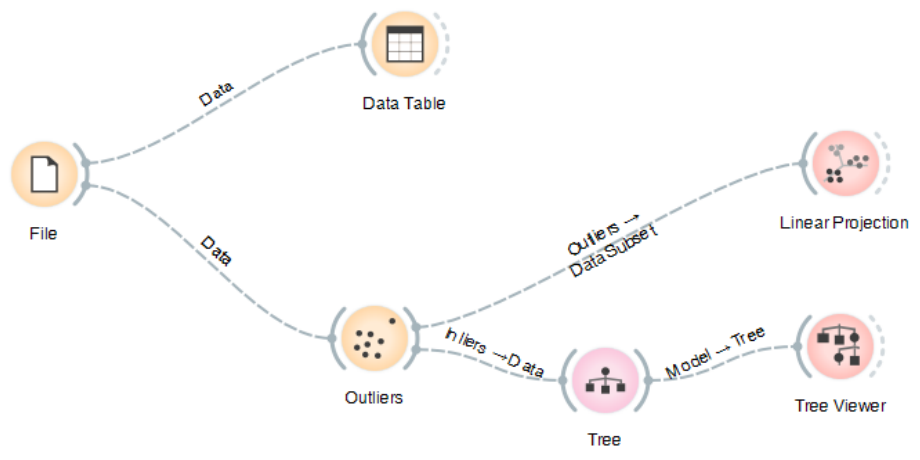

Figure 2. Classification model.

When the classification algorithm functions, data were distributed in two data sets consisting of training data and test data. The algorithm runs ten times and produces a classification model, as shown in Figure 3. 
Citra KURNIAWAN, Punaji SETYOSARI, Waras KAMDI, Saida ULFA. Classification of engineering students' self-efficacy towards visual-verbal preferences using data mining methods

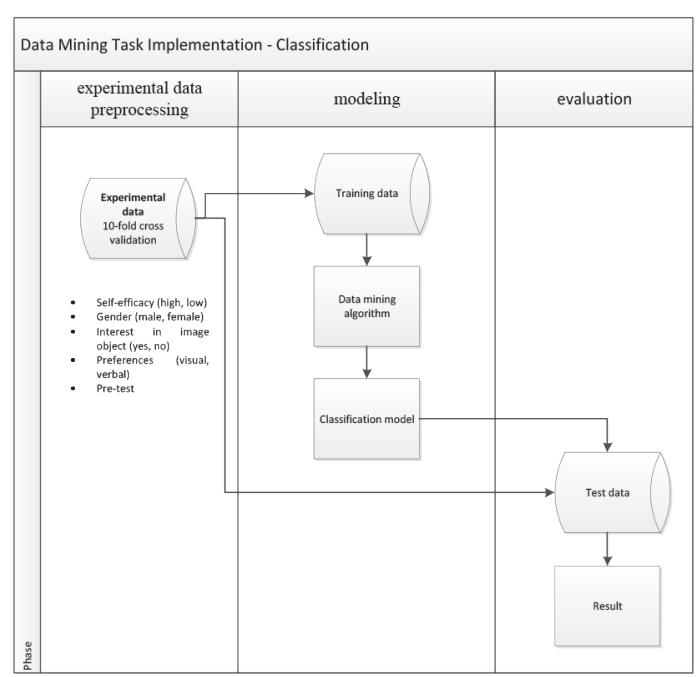

Figure 3. Data mining task implementation-classification.

The model classification in Figure 2 shows the class of data grouped based on the similarity of attributes to form a decision tree model. Outliner data were processed by the linear projection method. This method displays linear projections from classes labelled data. The projection in question is to generalize graphical projections and consider the effect of projections on geographical objects (Orange Data Mining, 2015). Rules classify attributes and attributes by making algorithm models in decision making. The algorithm for building a decision tree model can be seen in Figure 4.

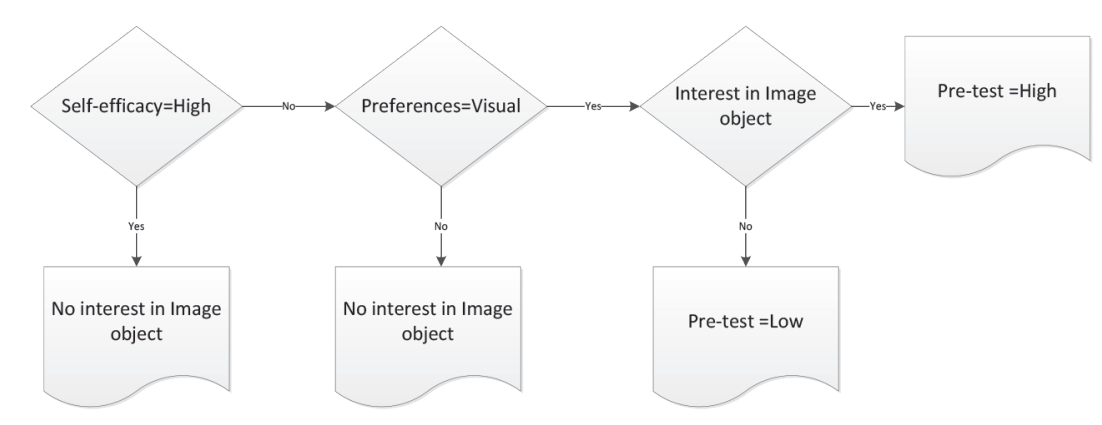

Figure 4. Model of a decision tree classifier.

The decision tree model in this research predicted the possibility of a class formed by the attributes possessed by the instance. The class was the status owned by the instance. The Class is often referred to as conclusions from data. Attributes were information that a class has. The decision tree model can be seen as follows:

If self-efficacy='high' then interest in image object='no'

Else if preferences=' visual.'

If self-efficacy='high' and preferences=' visual 'then interest in the image object

Else if pre-test='high' 
Citra KURNIAWAN, Punaji SETYOSARI, Waras KAMDI, Saida ULFA. Classification of engineering students' self-efficacy towards visual-verbal preferences using data mining methods

OF EDUCATION

IN THE $21^{\text {st }}$ CENTURY

Vol. 77, No. 3, 2019

354

\section{Research Results}

The number of instances in this research was 250 data instances. Each instance has a class, namely self-efficacy, gender, interest in the object image, and preference. This research uses data mining methods with classification techniques to identify classes, attributes, and examples. Research data can be seen, as shown in Figure 5.

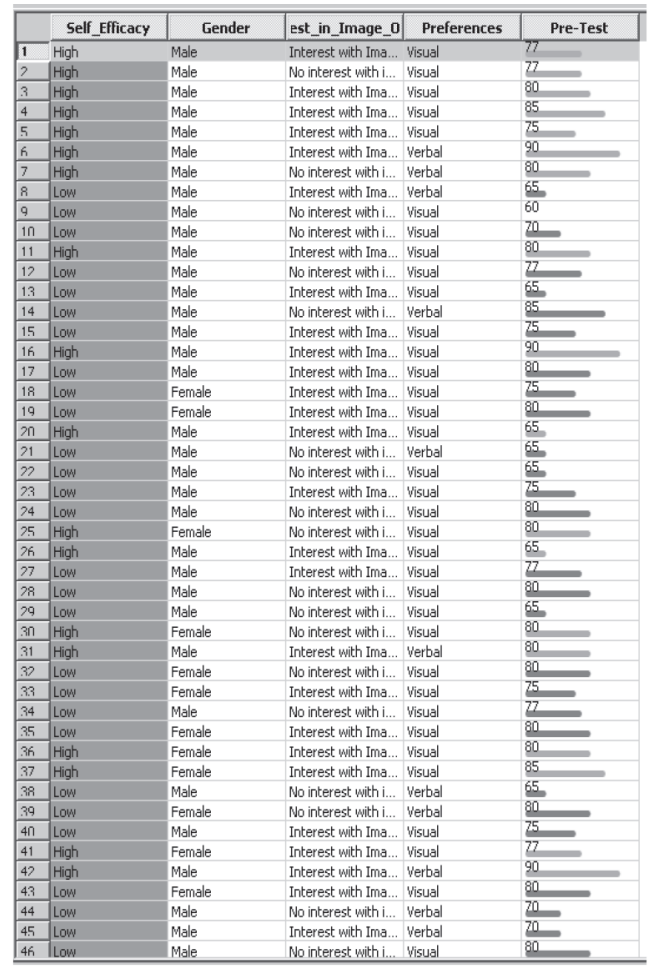

Figure 5. Instance data of the research.

Figure 5 shows an example of data in each class with each pre-test value. The Class has 105 high-value attributes, while the class that had a "low" attribute has an instance of 145 . The distribution of self-efficacy can be seen in Figure 6. 
Citra KURNIAWAN, Punaji SETYOSARI, Waras KAMDI, Saida ULFA. Classification of engineering students' self-efficacy towards visual-verbal preferences using data mining methods

PROBLEMS

OF EDUCATION

IN THE $21^{\text {st }}$ CENTURY

Vol. 77, No. 3, 2019

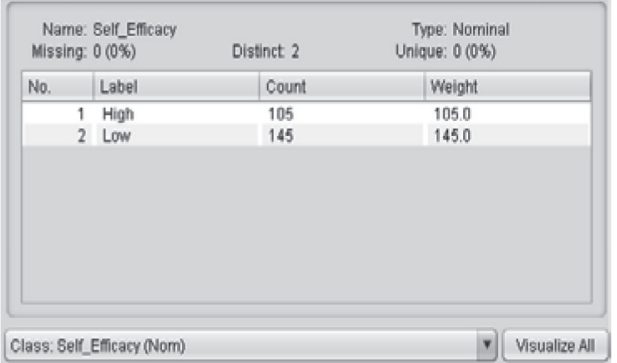

355

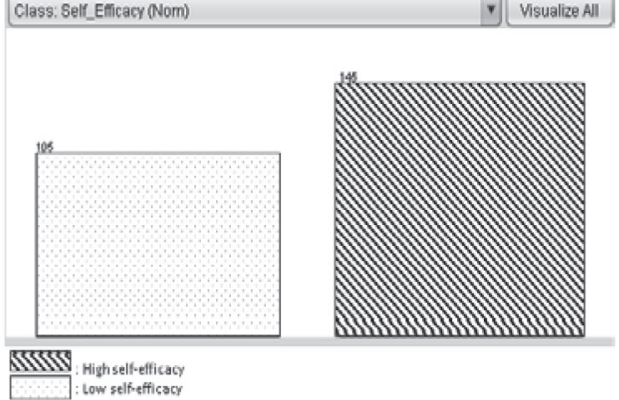

\section{Figure 6. Class of self-efficacy.}

The Class "gender" had a distribution of 'male' attributes consisting of 178 instances and 'female' consisting of 72 instances. The distribution of the class "gender" can be seen in Figure 7.
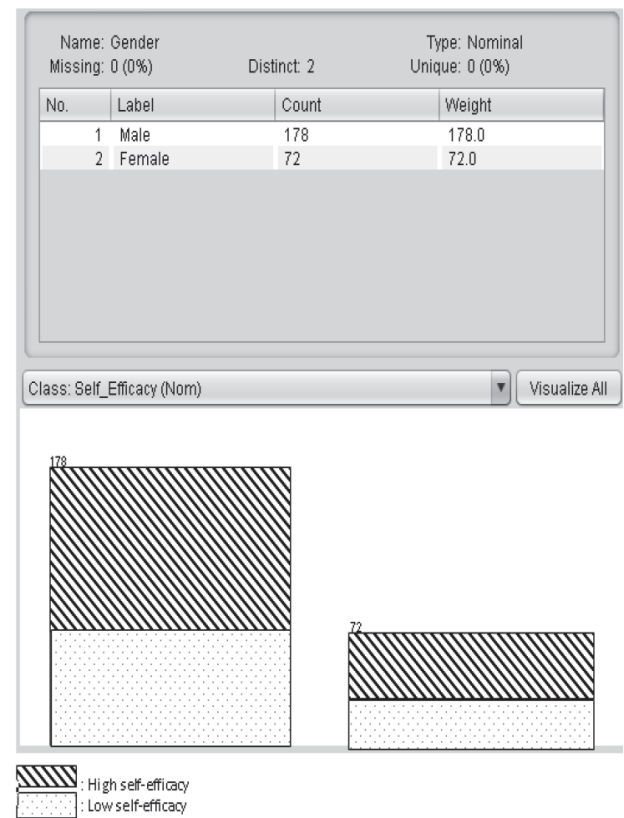

Figure 7. Class of gender.

Class "interest in the image" had a distribution of attributes 'yes' consisting of 145 instances and 'no' consisting of 105 instances. The distribution of the class "interest in the image" can be seen in Figure 8. 
Citra KURNIAWAN, Punaji SETYOSARI, Waras KAMDI, Saida ULFA. Classification of engineering students' self-efficacy towards visual-verbal preferences using data mining methods

OF EDUCATION

IN THE $21^{\text {st }}$ CENTURY

Vol. 77, No. 3, 2019

356
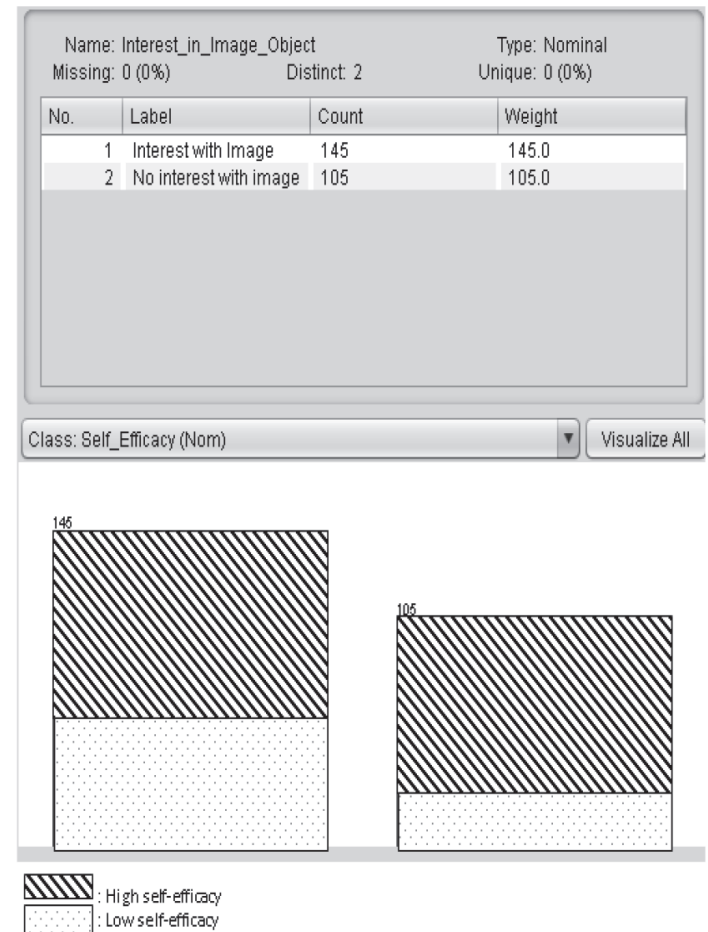

Figure 8. Class of interest in the image.

Figure 9 shows that class "preferences" had a distribution of 'visual' attributes as many as 180 instances, while 'verbal' attributes have as many as 70 instances.
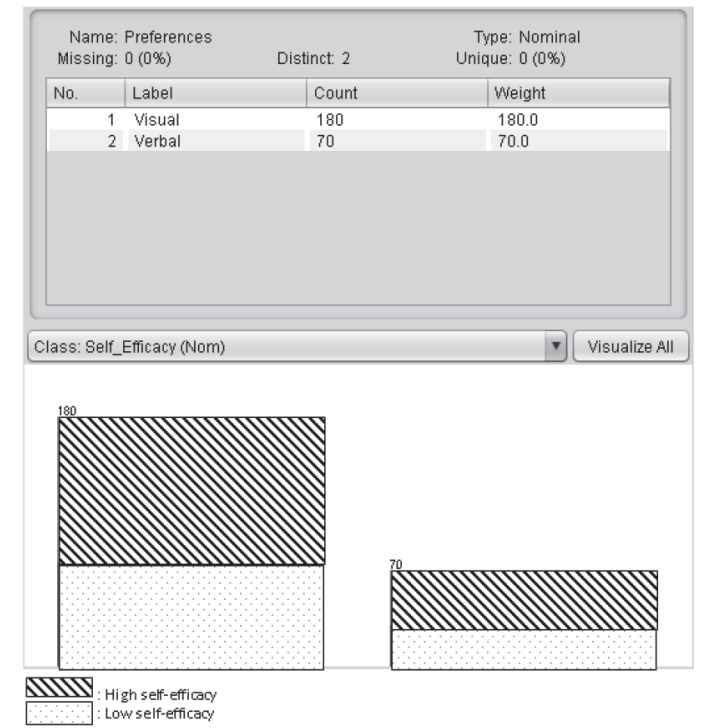

Figure 9. Class of preferences.

Participants involved in this research then followed the pre-test to test the initial ability level. The minimum value obtained by participants was 60 , and the maximum value obtained is 95, where the mean value is 76.288, and the standard deviation is 8.184, as shown in Figure 10. 
Citra KURNIAWAN, Punaji SETYOSARI, Waras KAMDI, Saida ULFA. Classification of engineering students' self-efficacy towards visual-verbal preferences using data mining methods

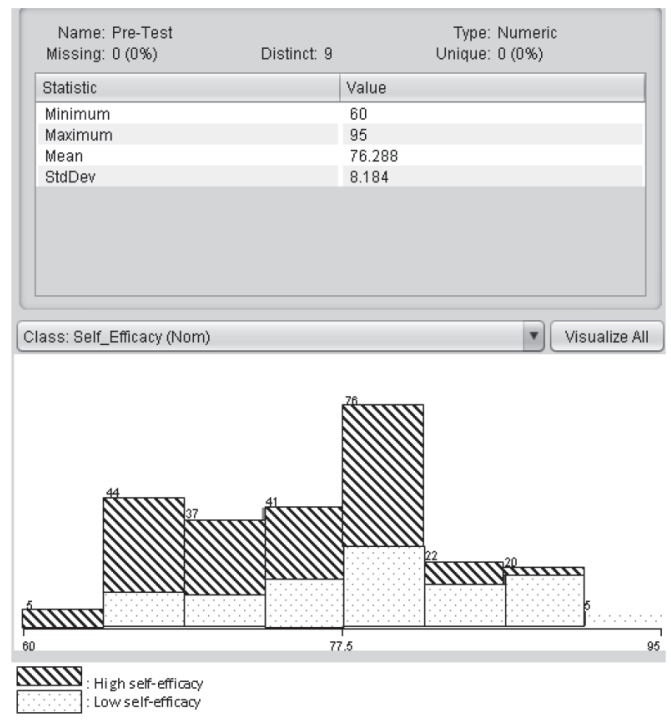

Figure 10. Means of pre-test.

\section{J48 Classifier Analysis}

The J48 classifier is a data mining method that implements a C4.5 algorithm to build a decision tree model. The decision tree model is created to form a classification model (Bhuvaneswari, Prabaharan, \& Subramaniyaswamy, 2015). The level of accuracy obtained in this research is $66 \%$, and the mean absolute error (MAE) is 0.3855 . MAE serves to measure the accuracy of predictions by averaging errors (the absolute value of errors). The analysis process in this section uses WEKA data mining to form a classification model. The classification process in WEKA data mining produces a confusion matrix. The confusion matrix is a method for measuring classification performance. The classification system performance describes how well the system classifies data. The confusion matrix can see the results of 2 lines. The first line, "41 64" shows that there are $(41+64)$ instances class self-efficacy "high" and all right are classified as self-efficacy 'high." In the second line, "21 124" shows that there are $(21+124)$ instances class self-efficacy 'low' and all are classified as self-efficacy 'low,' as in Figure 11. 
Citra KURNIAWAN, Punaji SETYOSARI, Waras KAMDI, Saida ULFA. Classification of engineering students' self-efficacy towards visual-verbal preferences using data mining methods

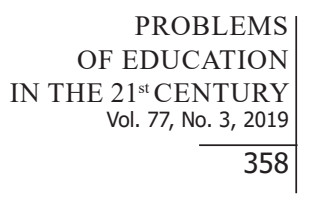

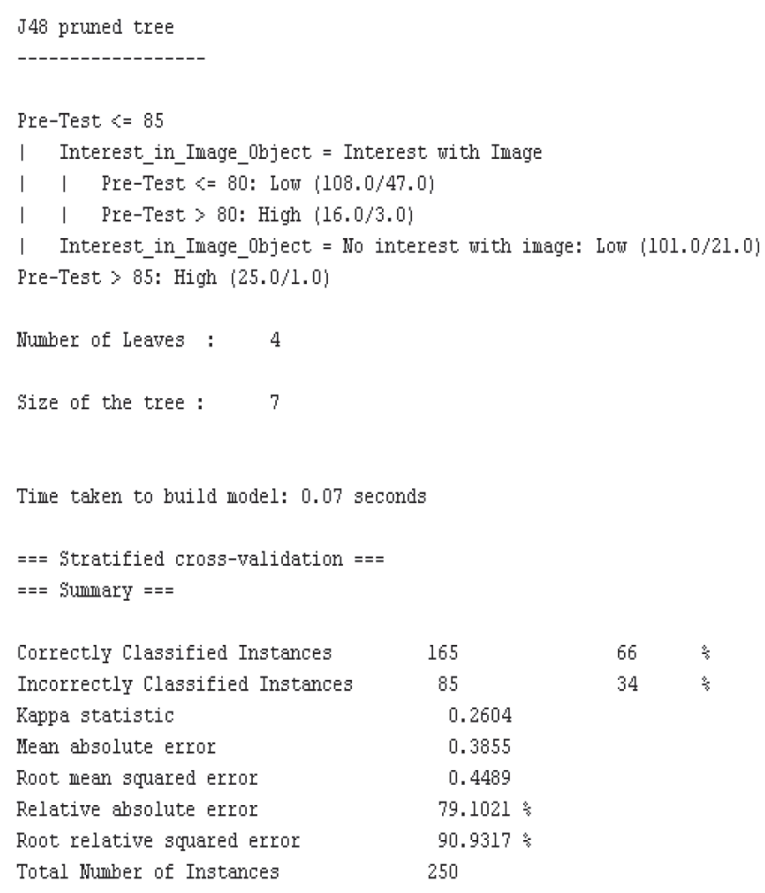

$===$ Detailed iccuracy By Class $===$

$\begin{array}{llllllllll} & \text { TP Rate } & \text { FP Rate } & \text { Precision } & \text { Recall } & \text { F-Measure } & \text { MCC } & \text { R0C Area } & \text { PRC Area } & \text { Class } \\ & 0.390 & 0.145 & 0.661 & 0.390 & 0.491 & 0.281 & 0.706 & 0.663 & \text { High } \\ \text { Weighted Avg. } & 0.855 & 0.610 & 0.660 & 0.855 & 0.745 & 0.281 & 0.706 & 0.727 & \text { Low } \\ & 0.660 & 0.414 & 0.660 & 0.660 & 0.638 & 0.281 & 0.706 & 0.700 & \end{array}$

$==$ Confusion Matrix $===$

a $b$ <-- classified as

$41 \quad 64$ । a $=$ High

21124 । $\quad \mathrm{b}=$ Low

Figure 11. Confusion matrix.

\section{Data visualization Analysis}

The research used data visualization with a decision tree and a linear projection approach to obtain a classification model. Linear projection is a machine learning method that refers to the number of populations from an instance. The linear projection method presents information about statistical correlations, about the linearity of specific aggregate values. Learning preferences of students have a relationship with student interest in images, while the level of self-efficacy does not correlate with the visual-verbal preferences, as shown in Figure 12. 
Citra KURNIAWAN, Punaji SETYOSARI, Waras KAMDI, Saida ULFA. Classification of engineering students' self-efficacy towards visual-verbal preferences using data mining methods

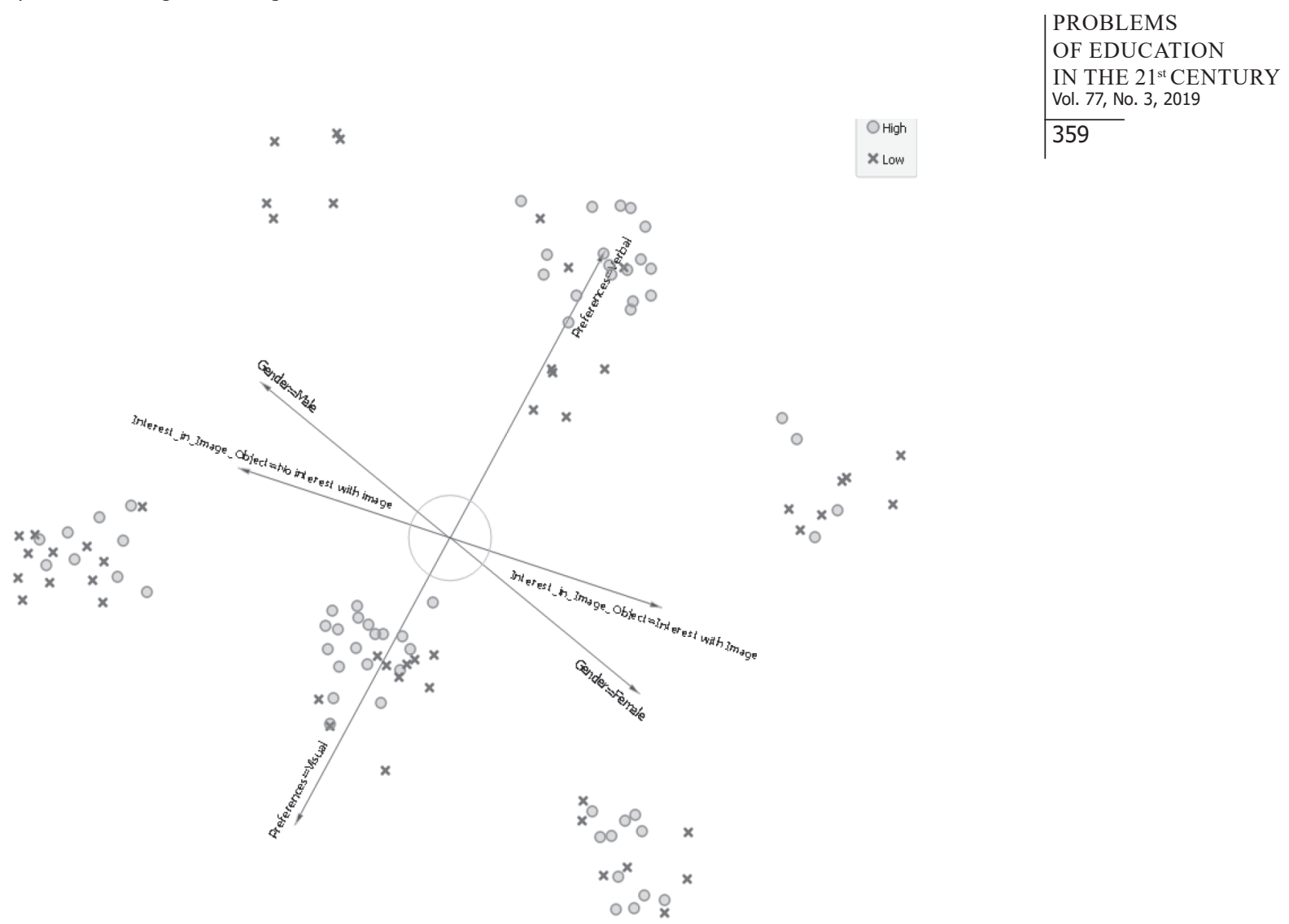

Figure 12. Linear projection of data visualization obtained for the data class.

Figure 12 shows that male students have more interest in images when compared to female students. The result is reinforced by the results that show that male students who have visual preferences have more numbers compared to female students. Grouping in the decision tree is divided based on the value of achievement on the results of the pre-test, consisting of two groups, namely students with a value of $>85$ and students with a value of $\leq 85$. Students who have pre-test $>85$ have high self-efficacy. Whereas in students who have the results of pre-test $\leq$ 85 are distinguished based on the students' interest in the image, as shown in Figure 13.

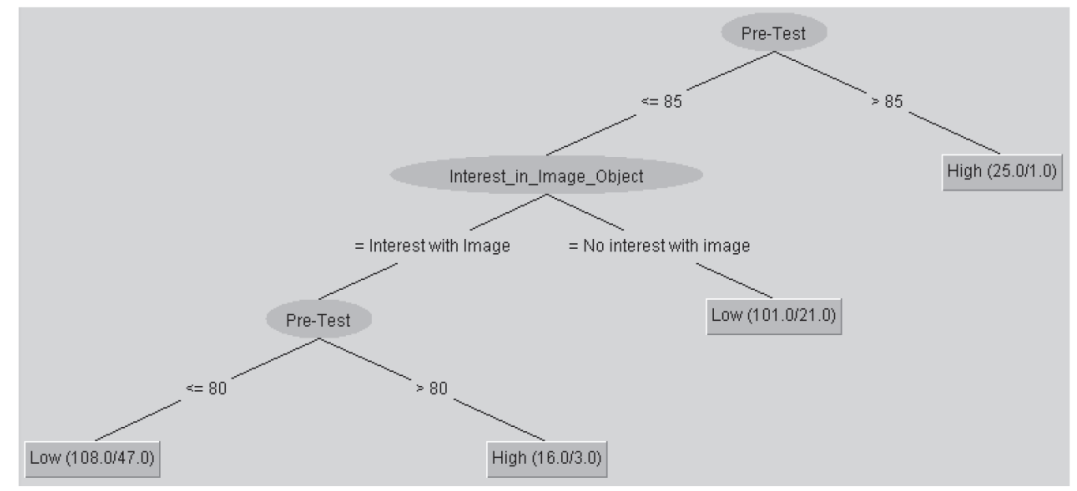

Figure 13. The Decision tree of correlation learning outcomes with the results of the pre-test and self-efficacy. 
Citra KURNIAWAN, Punaji SETYOSARI, Waras KAMDI, Saida ULFA. Classification of engineering students' self-efficacy towards visual-verbal preferences using data mining methods

IN THE $21^{\text {st }}$ CENTURY Vol. 77 , No. 3, 2019

360
Figure 13 shows that interest in images can affect the results of pre-test $(>80)$ if students have high self-efficacy. So, it can be concluded that high self-efficacy directly affects the achievement of the pre-test results, on the other hand, the interest in images and visual-verbal preferences do not influence the achievement of the results of the pre-test. Students who have visual preferences with interest in images can get good pre-test results if there is a high selfefficacy factor.

\section{Discussion}

This research showed that participants who have a low level of self-efficacy are $58 \%$, and participants who have a high level of self-efficacy are $42 \%$. However, the results of the research showed that there is a correlation between the level of efficacy of visual-verbal preferences, as indicated by the variation of the results obtained, as shown in Figure 14.

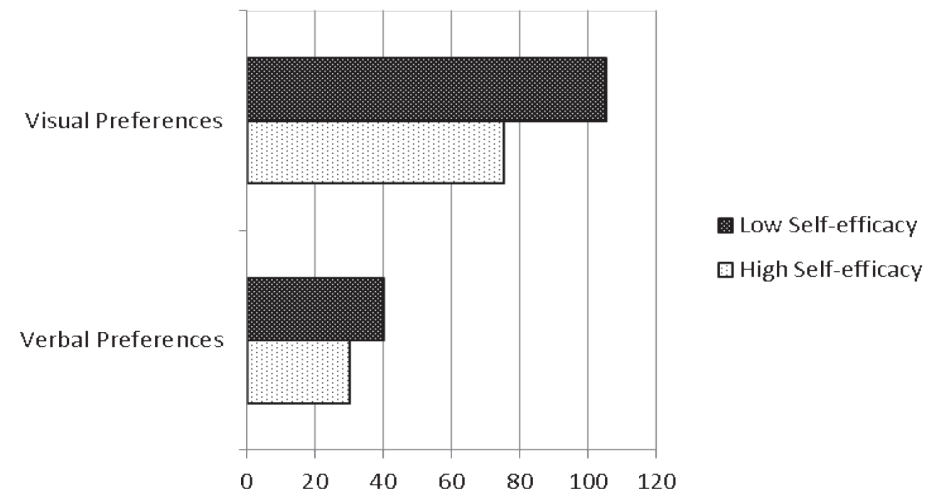

\section{Figure 14. Overall accuracy of classifiers.}

The decision tree method can present a correlation and classification model based on the similarity of attributes of data instances. It is consistent with previous research that shows that this method can help establish a classification model for experimental data (Kabakchiev et al., 2017). The classification model classifies data instances with their respective attributes (Demšar et al., 2013; Singh, Naveen, \& Samota, 2013). The decision tree method in this study can predict groups in each example where each sample is grouped according to the associated agreement (results see Figure 13). It agrees with Apte and Weiss (1997), which state that classifications in data mining are used to predict problems and group problems based on the objectives to be used (Apte \& Weiss, 1997). Decision tree involves the use of training sets to build problem prediction models and classify input data (Singh et al., 2013). The classification model was developed based on predictive algorithms by classifying populations into branches consisting of root nodes, internal nodes, and leaf nodes (Yan-yan Song \& Ying Lu, 2015).

An additional alternative method that can be used is the linear projection method. Linear projection can display statistical projection information and describe the tendency of one class to another class. The implementation of data mining methods, such as decision tree-classification, and linear projection, are beneficial for measuring correlations between classes and attributes of experimental data.

This research found that self-efficacy affected the results of the pre-test which agreed with what was revealed by Abosede and Adesanya, who revealed that self-efficacy influences performance and problem-solving abilities (Abosede \& Adesanya, 2017). Other studies also found results that engineering self-efficacy had a significant correlation with academic achievement (Aleta, 2016). 
Citra KURNIAWAN, Punaji SETYOSARI, Waras KAMDI, Saida ULFA. Classification of engineering students' self-efficacy towards visual-verbal preferences using data mining methods

\section{Conclusions}

Classification techniques in data mining methods designed to classify data instances aim to build a classification model for experimental data. Classification forms a decision tree to group data instances based on attribute attributes. The class results of the class form the model according to the prediction of the problem presented. This research involved engineering selfefficacy towards visual-verbal preferences about the results of the pre-test. There is a need for analysis of experimental results such as self-efficacy towards the tendency toward visual-verbal. This research proposes an alternative method to measure the correlation of self-efficacy with a visual-verbal preferences approach called the J48 classifier technique and linear projection.

J48 classifier is an algorithm used to construct a decision tree with a statistical classifier, while a linear projection presents information about the correlation of linearity to several measured variables. The measurement results show that self-efficacy correlates with the results of visual-verbal preferences. The proposed method can also be applied to the measurement of correlation with more classes and large data instances in the database. This research found that data mining methods, especially decision trees, were able to be used in analysing correlations between several variables. The decision tree method can be used as an alternative method besides the statistical method in measuring the correlation between variables. Further research is expected to develop other data mining methods specifically for processing educational data.

\section{Acknowledgments}

This research is supported by the Domestic Postgraduate Education Scholarship (BPPDN) from the Ministry of Research, Technology, and Higher Education.

\section{References}

Abernethy, M. (2010). Data mining with WEKA, Part 2: Classification and clustering (No. 2). IBM developer Works. Retrieved from ibm.com/developerWorks/.

Abosede, S. C., \& Adesanya, A. O. (2017). Contributions of self-efficacy and problem-solving skills on secretaries' job performance in Ogun State public service, Nigeria. Journal of Education and Practice, 8(11), 109-116.

Aleta, B. T. (2016). Engineering self-efficacy contributing to the academic performance of AMAIUB engineering students: A qualitative investigation. Journal of Education and Practice, 7(27), 5361.

Apte, C., \& Weiss, S. (1997). Data mining with decision trees and decision rules. Data Mining, 13. https:// doi.org/10.1016/S0167-739X(97)00021-6.

Bandura, A. (1994). Self-Efficacy. In I. V. S. Ramachaudran (Ed.), Encyclopedia of human behavior (Vol. 4, pp. 71-81). New York: Academic Press. https://doi.org/10.1002/9780470479216.corpsy0836.

Bandura, A. (1997). Self-efficacy: The exercise of control. Harvard Mental Health Letter (Vol. 13). New York: W.H Freeman Company. https://doi.org/10.1007/SpringerReference_223312.

Bandura, A. (2006). Guide for constructing self-efficacy scales. In F. Pajares \& T. Urdan (Eds.), SelfEfficacy beliefs of adolescents (pp. 307-337). Greenwich: Information Age Publishing.

Bhuvaneswari, T., Prabaharan, S., \& Subramaniyaswamy, V. (2015). An effective prediction analysis using J48. ARPN Journal of Engineering and Applied Sciences, 10(8), 3474-3480. Retrieved from www.arpnjournals.com.

Boswell, S. S. (2013). Undergraduates' perceived knowledge, self-efficacy, and interest in social science research. The Journal of Effective Teaching, 13(2), 48-57.

Carberry, A. R., Hee-Sun, L., \& Ohland, M. W. (2010). Measuring engineering design self-efficacy. Journal of Engineering Education, 99(1), 71-79. https://doi.org/10.1002/j.2168-9830.2010. tb01043.x.

Cisco Systems. (2003). Cisco Networking Academy Program CCNA 1 and 2 Companion Guide. Indianapolis: Cisco Press. 
Citra KURNIAWAN, Punaji SETYOSARI, Waras KAMDI, Saida ULFA. Classification of engineering students' self-efficacy towards visual-verbal preferences using data mining methods

\section{PROBLEMS \\ OF EDUCATION \\ IN THE $21^{\text {st }}$ CENTURY Vol. 77, No. 3, 2019}

362

Demšar, J., Curk, T., Erjavec, A., Hočevar, T., Milutinovič, M., Možina, M., .. Zupan, B. (2013). Orange: Data Mining Toolbox in Python. Journal of Machine Learning Research, 14, 23492353.

Hutchison, M. A., Follman, D. K., \& Bodner, G. M. (2005). Shaping the self-efficacy beliefs of firstyear engineering students: What is the role we play? School of Engineering Education Graduate Student Series, 12. Retrieved from http://docs.lib.purdue.edu/enegs/12.

Jordan, K. L., Amato-henderson, S., Sorby, S. A., \& Donahue, T. L. H. (2011). Are there differences in engineering self-efficacy between minority and majority students across academic levels? In New Research \& Trends for Minorities in Engineering (pp. 13-26). Vancouver: American Society for Engineering Education. Retrieved from https://www.asee.org/public/conferences/1/papers/659/ download.

Kabakchiev, C., Kabakchieva, D., Garvanov, I., Behar, V., Kabakchiev, K., Rohling, H., ... \& Yarovoy, A. (2017). Data mining classification of cars based on GPS shadows in Forward Scatter Radar systems. In The 18th International Radar Symposium IRS 2017. Prague: DGON. https://doi. org/10.23919/IRS.2017.8008217.

Kirby, J. R., Moore, P. J., \& Schofield, N. J. (1988). Verbal and visual learning styles. Contemporary Educational Psychology, 13(May 2014), 169-184. https://doi.org/10.1016/0361476X(88)90017-3.

Kurniawan, C., Setyosari, P., Kamdi, W., \& Ulfa, S. (2018). Electrical engineering student learning preferences modelled using k-means clustering. Global Journal of Engineering Education, 20(2), $140-145$.

Marra, R., \& Bogue, B. (2006). Women engineering students' self efficacy - A longitudinal multiinstitution study. In Proceedings of the 2006 WEPAN Conference (pp. 67-78). Pittsburgh: WEPAN-Women in Engineering Programs and Advocates Network. Retrieved from https:// journals.psu.edu/wepan/article/view/58479/58167.

Orange Data Mining. (2015). Linear Projection: A linear projection method with explorative data analysis. Retrieved September 7, 2018, from https:/docs.orange.biolab.si/3/visual-programming/widgets/ visualize/linearprojection.html.

Pektaş, Ş. T. (2013). Correlations between the visualizer/imager cognitive style and achievement in digital modeling tasks. Procedia - Social and Behavioral Sciences, 116(2014), 5055. https://doi. org/10.1016/j.sbspro.2014.01.1072.

Peterson, M. O. (2016). Schemes for integrating text and image in the science textbook: Effects on comprehension and situational interest. International Journal of Environmental and Science Education, 11(6), 1365-1385. https://doi.org/10.12973/ijese.2016.352a.

Plass, J. L., Chun, D. M., Mayer, R. E., \& Leutner, D. (1998). Supporting visual and verbal learning preferences in a second-language multimedia learning environment. Journal of Educational Psychology, 90(1), 25-36. https://doi.org/10.1037/0022-0663.90.1.25.

Richardson, A. (1977). Verbalizer-Visualizer: A cognitive style dimension. Journal of Mental Imagery, $1,109-126$.

Schunk, D. H. (2003). Self-efficacy for reading and writing: Influence of modelling, goal setting, and selfevaluation. Reading and Writing Quarterly, 19, 159-172.

Singh, D., Naveen, H., \& Samota, J. (2013). Analysis of data mining classification with decision tree technique. Global Journal of Computer Science and Technology, 13(13), 1-6.

Sudatha, I. G. W., Degeng, I. N. S., \& Kamdi, W. (2018). The Effect of Visualization Type And Student Spatial Abilities On Learning Achievement. Journal of Baltic Science Education, 17(4), 551-563.

Witten, I. H., Frank, E., Hall, M. A., \& Pal, C. J. (2017). Data Mining: Practical machine learning tools and techniques. (C. Kent, Ed.) (4th ed.). Cambridge: Morgan Kaufmann Publishers. https://doi. org/10.1016/C2009-0-19715-5.

Wu, C.-S., Tsai, L., \& Wang, P. (2011). Correlation between technological creativity, self- efficacy and knowledge sharing among athletes. International Journal of Management and Marketing Research, 4(2), 77-84.

Yan-yan Song, \& Ying Lu. (2015). Decision tree methods: Applications for classification and prediction. Shanghai Archives of Psychiatry, 27(2), 130-135. https://doi.org/10.11919/j.issn.10020829.215044 . 
Citra KURNIAWAN, Punaji SETYOSARI, Waras KAMDI, Saida ULFA. Classification of engineering students' self-efficacy towards visual-verbal preferences using data mining methods

Received: April 09, 2019

Accepted: June 10, 2019

PROBLEMS

OF EDUCATION

IN THE $21^{\text {st }}$ CENTURY

Vol. 77, No. 3, 2019

363

\section{Citra Kurniawan Student of Graduate School, State University of Malang, Malang, Indonesia \\ (Corresponding author) E-mail: airakurniawan@gmail.com}

\begin{tabular}{|ll} 
Punaji Setyosari & $\begin{array}{l}\text { Professor at the Department of Educational Technology, State University of Malang, } \\
\text { Malang, Indonesia. } \\
\text { E-mail: punaji.setyosari.fip@um.ac.id }\end{array}$ \\
\hline Waras Kamdi & $\begin{array}{l}\text { Professor at the Department of Mechanical Engineering Education, } \\
\text { State University of Malang, Malang, Indonesia. } \\
\text { E-mail: waras.ft@um.ac.id }\end{array}$ \\
Saida Ulfa & $\begin{array}{l}\text { Assistant Professor at the Department of Mechanical Engineering Education, State } \\
\text { University of Malang, Malang, Indonesia. } \\
\text { E-mail: saida.ulfa.fip@um.ac.id }\end{array}$
\end{tabular}

